SIR-We wish to bring to the attention of the scientific community the circumstances that led to the cancellation of the Third International Workshop of the Group for Aquatic Primary Productivity (GAP) scheduled for 29 April-4 May in Durban, South Africa.

GAP was established in 1980 under the aegis of the International Society for Limnology and the International Association for Ecology to provide a forum for oceanographers and limnologists studying theoretical and methodological aspects of primary production in marine and fresh waters. Successful GAP Workshops were held in Konstanz, West Germany, in 1982 and Haifa, Israel, in 1984.

When the International Committee of GAP accepted the invitation of our South African colleagues to hold the third workshop in that country, we were aware of potential problems. It was clear that some scientists, as individuals, would choose not to attend an event in a country whose governmental racial policies are morally repugnant to most, if not all, of us. This viewpoint is understandable and such a decision is the prerogative of each individual.

We did not expect, however, to be faced with a situation in which a significant number of our colleagues who had expressed their intention to attend the workshop were expressly forbidden to do so by their superiors or administrations. In at least one case, a young scientist was threatened with jeopardizing his future career if he participated in any capacity at the GAP meeting. As a result of such pressures, the number of prospective participants in the workshop became so limited that we were reluctantly forced to cancel the meeting.

GAP is a scientific organization affiliated to the International Council of Scientific Unions (ICSU). For many years, ICSU has striven to guarantee the freedom of bona fide scientific exchange. The Principles of Universality as formulated by the ICSU Standing Committee on the Free Circulation of Scientists are basic to all ICSU objectives and have been reaffirmed by the latest ICSU General Conference in Ottawa in October 1984. Actions that deny scientists' freedom to travel to legitimate scientific activities are a flagrant and dangerous violation of these principles.

Science is an international endeavour, unfortunately tainted by political realities. It behoves the scientific community to be vigilant in maintaining its rights of free exchange and circulation. The forced cancellation of the GAP Workshop has no impact on the South African government's racial policies and only serves to increase the isolation of our colleagues who are largely counted among the liberalizing forces there. We can only caution the scientific community that, alas, this will not be the last encroachment upon the Principles of Universality and advise vigorous and early protest in future instances.

TOM BERMAN (Chairman, GAP International

\section{Israel Oceanographic} Committee)

\& Limnological Research Ltd,

The Yigal Allon Kinneret

Limnological Laboratory,

POB 345,

Tiberias, Israel

\section{RGO move OK}

SIR-The decision of the Science and Engineering Research Council (SERC) to move the Royal Greenwich Observatory ( $\mathrm{RGO}$ ) to the University of Cambridge is a historic decision, whose consequences are not fully realized by Nature. Your leading article (Nature 322, 1; 1986) belittles the SERC choice as being based on the unwillingness of RGO staff to travel north of the Trent. This point-scoring ignores the facts that ex-RGO staff hold positions at the Royal Observatory, Edinburgh (ROE) - there has been a good history of staff interchange between RGO and ROE - and that large numbers of the RGO staff spend a large proportion of their time working and living overseas on La Palma and elsewhere. Jerry Sellwood's pro-Manchester letter $(322,106 ; 1986)$ comments on the decision by raising issues irrelevant to astronomy, such as national policies of regional development and an alleged prejudice by everybody against Manchester.

In deciding to move RGO to Cambridge, SERC is consolidating one of the world's great centres for astronomy, bringing radio, theoretical and optical astronomy together with the instrument science and engineering on which the progress of astronomy depends. It is true that many RGO staff (including ourselves) and many British astronomers opposed the move, and that the University of Sussex's astronomy programme could be damaged, an issue that SERC should address in the future. But we believe that of the choices SERC set itself the decision to move to Cambridge is best for British astronomy as a whole.

We hope that the Secretary of State for Education and Science, taking proper account of the financial arguments, will stick with the clear scientific decision of SERC. Further vacillation would prolong the problems for RGO and British astronomy; surely astronomers in the United Kingdom now need to put this matter be- hind them and move confidently into the twenty first century, getting on with the tasks at hand.

Bob Argyle, Charles Jenkins, Derek Jones, Robert Laing, Tom Marsh, Bill Martin, Paul Murdin, Max Pettini, Hans Schild, Keith Taylor, Roberto Terlevich, Kerth Tritton, Jasper Wall Royal Greenwich Observatory,

Herstmonceux Castle,

Hailsham, East Sussex BN27 1RP

\section{Japanese education}

SIR-I would like to add to Alun Anderson's News item (Nature 321, 6; 1986) on Japanese education from the viewpoint of an undergraduate student. The University Council recently decided to increase the opportunity for applicants to take the university entrance examination with the aim of increasing the flexibility of the universities. But I wonder if it will not produce another worse result; to standardize the quality of students and to rank more clearly all of the universities. The educational industry will also gain power, worsening the situation we call "the examination war ordeal". Even now, many applicants choose their universities only for their name value, and after entering have no clear object of study. To solve these problems, the universities must be given more independence and autonomous rights.

The PhD glut ("overdoctors" or unemployed $\mathrm{PhD}$ holders) is another difficult problem. If one wants to get a post in a university, one must put up with years as an overdoctor because of the low staff turnover. Otherwise one must move to private enterprise. For this reason, I think, Japanese basic research cannot develop fully.

Faculty of Science,

ShinJi Hirano

Kyoto University,

Kitashirakawa, Sakyo-ku,

Kyoto 606, Japan

Alun Anderson replies: I agree with $\mathrm{Mr}$ Hirano. All state universities have traditionally held their examinations on the same day, effectively preventing anyone from applying to more than one state university in any one year, a situation that commits candidates to the uncertain task of selecting a university with a pass mark thought likely to match the candidate's likely examination mark. Universities are now to be divided into groups with examinations on different days. But this may not solve the problem of universities forming a hierarchy according to their pass marks. Kyoto University law school, for example, fears that in future all its candidates will take both Tokyo and Kyoto University law school examinations and all those accepted for Tokyo will go there. That could have the immediate effect of converting Kyoto into a "secondrank" institution. 